\title{
O ensino de línguas estrangeiras e a sociedade
}

\author{
Francisco Carlos Fogaça \\ Universidade Estadual de Londrina - UEL \\ Telma Nunes Gimenez \\ Universidade Estadual de Londrina - UEL
}

\begin{abstract}
Este trabalho tem por objetivo discutir a relação entre o ensino de línguas estrangeiras e a sociedade, por meio de três tendências político-filosóficas: a) educação como redenção, que vê a prática educacional como uma forma de redimir a sociedade de suas desigualdades; b) a visão reprodutivista, que vê a educação como forma de reproduzir as condições de produção da sociedade, mantendo suas desigualdades; c) a tendência transformadora, que entende que a educação tem um importante papel político e transformador a partir das necessidades e desejos das classes dominadas, buscando sua emancipação. Documentos oficiais como os Parâmetros Curriculares Nacionais e as Orientações Curriculares Nacionais foram analisados para identificação dessas tendências. Os documentos revelaram traços das tendências redentora e transformadora, configurando os embates deflagrados por uma sociedade marcada por exclusão e diferentes interesses.
\end{abstract}

This study aims at discussing the relationship between foreign language teaching and society through three political and philosophical approaches: a) education as the redemption of society, which sees it as a solution to all social inequalities; b) education as the as the reproduction of the social relations of production, which aims at keeping the status quo; c) a transformative approach to education, which attributes an important political and emancipatory role to education and takes into account the needs and ambitions of the dominated classes. This study analyzed some official documents issued by the Ministry of Education, which guide the educational process in this country, in the light of the three perspectives. The documents revealed traces of redemption and transformation as key elements in the learning/teaching of foreign languages, a result that translates the struggles of an unequal society.

\section{Introdução}

Entender a relação entre educação e sociedade ${ }^{1}$ pode nos ajudar a entender o papel desempenhado pelo ensino de línguas estrangeiras (LEs)

\footnotetext{
${ }^{1}$ Sociedade é aqui entendida como o conjunto de indivíduos que compartilham objetivos comuns e se relacionam de modo interdependente.
} 
ao longo das últimas décadas no contexto brasileiro. O processo educacional está repleto de conceitos, valores, e finalidades que lhe dão sentido e direcionamento. O ensino de LEs, como parte do processo mais amplo da educação, está igualmente sujeito a esses valores, expressos de diversas formas, inclusive em documentos oficiais.

Podemos entender, de forma geral, o papel da educação na sociedade por meio de três tendências político-filosóficas, conforme postulado por Luckesi (1994): educação como redenção, educação como reprodução e educação como uma forma de transformação da sociedade. A primeira perspectiva vê a educação como uma forma de redimir a sociedade de suas mazelas, desigualdades e injustiças, ao tentar dar aos alunos uma formação ética, humanista e conteudista. A segunda vê na educação uma forma de refletir as condições de produção da sociedade, com foco na preparação para o mercado de trabalho, cujo objetivo é suprir as demandas desse mercado e da sociedade em geral. A terceira tendência não vê a educação nem como redentora e nem como reprodutora, mas como uma forma de transformar a sociedade, uma tendência emancipatória que pretende formar alunos críticos e participativos. Longe de representar tendências estanques, embora tão diversas em relação a valores e objetivos, elas coexistem nos dias de hoje: em uma mesma instituição podemos ter múltiplas representações do papel da educação e sua relação com a sociedade. Da mesma forma, documentos oficiais que procuram encapsular visões da sociedade a respeito dos valores que guiam o ensino de LEs expressam essas tendências, muitas vezes de forma contraditória, ora reforçando a perspectiva redentora - que acaba naturalmente reproduzindo e mantendo o status quo - ora a transformadora.

Neste texto nos propomos a analisar os objetivos para o ensino de LEs em três textos oficiais: os Parâmetros Curriculares para o Ensino Fundamental (PCNEF, 1998), as Orientações Curriculares para o Ensino Médio - Língua Estrangeira e as Orientações Curriculares para o Ensino Médio - Espanhol, à luz das três tendências, ao mesmo tempo que analisamos o percurso histórico do ensino de LEs no Brasil. Justifica-se essa escolha em função de serem esses os documentos em vigor para a educação básica, embora já haja movimento para atualização dos Parâmetros no Ensino Fundamental. 


\section{Educação como Redenção}

A tendência redentora vê a educação como uma forma de estabelecer uma harmonia entre os membros da sociedade, integrando aqueles que estiverem à margem. Nas palavras de Luckesi (1994, p. 38):

(...) a sociedade está "naturalmente" composta com todos os seus elementos; o que importa é integrar em sua estrutura tanto os novos elementos (novas gerações), quanto os que, por qualquer motivo, se encontram à sua margem. Importa, pois, manter e conservar a sociedade, integrando os indivíduos no todo social.

A sociedade vista dessa forma é concebida como harmoniosa; a marginalidade, que afeta alguns de seus membros, é um desvio que precisa ser corrigido. A educação surge, então, como um instrumento de correção dessas distorções da sociedade, na tentativa de superar a marginalidade "evitando sua desagregação, e, mais do que isso, garantindo a construção de uma sociedade igualitária" (SAVIANI, 1986, p. 8).

Essa visão pode ser considerada ingênua, ou "não-crítica" (SAVIANI, 1986), uma vez que considera a educação isenta de uma ação política, como se nenhum grupo social dela se beneficiasse para seus interesses próprios. A educação é vista como uma instância exterior e autônoma em relação à sociedade, dando-lhe forma e garantindo a construção de um mundo mais justo.

Saviani (1986) cita como exemplos dessa concepção redentora da educação: a pedagogia tradicional, a pedagogia nova e a pedagogia tecnicista. A essas três concepções poderíamos também juntar a perspectiva educacional do neoliberalismo, sobretudo a partir dos anos 80 , que poderíamos chamar de pedagogia neoliberal.

\section{A pedagogia tradicional}

A pedagogia tradicional data do início do século XIX - os enciclopedistas da Revolução Francesa - e vê a educação como um direito de todos e um dever do Estado, consolidando uma sociedade burguesa emergente que busca vencer a barreira da ignorância para superar a condição de opressão do regime político anterior, a monarquia. A marginalização social a ser vencida pela educação se materializa, assim, na luta contra a ignorância.

No Brasil, conforme Franca (1952 apud LEFFA, 1999), durante o império colonial, o grego e o latim eram as disciplinas dominantes. As 
demais (como História e Geografia) eram normalmente ensinadas utilizando-se as línguas clássicas, em exercícios de tradução. Muito lentamente as LEs modernas foram adquirindo um status semelhante ao das línguas clássicas: inicialmente com a chegada da família real em 1808, depois com a criação do Colégio D. Pedro II em 1837 e, finalmente, com a reforma de 1855 .

Chagas (1967) salienta que as línguas modernas com maior prestígio no império eram o francês, o inglês e o alemão, de estudo obrigatório; o italiano foi excluído em 1870, ressurgindo mais adiante em caráter facultativo. Entre as línguas clássicas, o grego e o latim eram obrigatórios. A partir de 1915 o grego foi retirado do currículo, e o latim passou a ocupar a metade (ou até dois terços) das horas destinadas ao estudo de línguas.

Durante a República os idiomas vivos foram reduzidos a dois: francês e inglês, ou alemão, com uma média de três anos letivos para cada um. A carga horária semanal destinada ao ensino de línguas modernas no ensino básico foi sendo aos poucos diluída pelas diversas reformas antes de 1931, tendo chegado a 47 horas em 1892, terminando com 17 horas obrigatórias em 1929, caracterizando um notório desprestígio no ensino de línguas. Segundo Chagas (1967), isso deveu-se, em grande parte, às deficiências de ordem didática e ao "liberalismo suicida que reduzia a escola secundária brasileira à simples função de diplomar estudantes presunçosos e não raro analfabetos" (p. 108). A escola ficou relegada à função burocrática de aprovar e de fornecer diplomas, abstendo-se de sua função primordial de ensinar e educar.

\section{A Pedagogia Nova}

A pedagogia nova surge no final do século XIX, mantendo de pé a crença no poder da escola para corrigir as distorções sociais - não mais enfocando os ignorantes, mas agora os considerados "anormais". O alvo dessa pedagogia são inicialmente os indivíduos rejeitados socialmente, os que possuem deficiências neurofisiológicas, dando origem a uma pedagogia que enfatiza as diferenças individuais e a necessidade de aceitarmos essas diferenças. A descoberta de que os seres humanos são essencialmente diferentes leva à conclusão de que educação será vista como "um instrumento de correção da marginalidade na medida em que contribuir para a constituição de uma sociedade cujos membros, não importam as diferenças de quaisquer tipos, se aceitem mutuamente e se respeitem na sua 
individualidade específica" (SAVIANI, 1986, p. 12). Comparativamente à pedagogia tradicional, há o deslocamento de alguns eixos: do intelecto para o sentimento, do lógico ao psicológico, dos conteúdos para os processos pedagógicos (métodos), do professor para o aluno, do aprender ao aprender a aprender.

No Brasil, a reforma Francisco de Campos, de 1931, foi uma tentativa de resgatar a educação do declínio no qual se encontrava, propondo-se a democratizar a escola secundária. Extinguiu-se a freqüência livre, implantando-se o regime seriado obrigatório com vistas a preparar o aluno para a universidade - também por meio de cursos complementares de dois anos - e a dar-lhe uma formação integral. O novo currículo procurou manter o equilîbrio entre as ciências e as letras, "entre o clássico e o moderno, entre o humanismo e a técnica” (CHAGAS, 1967, p. 109).

Além disso, a diminuição na carga horária para o ensino de latim representou um aumento para o ensino das demais línguas estrangeiras. Nas palavras de Leffa (1999):

[e]m termos de conteúdo, foi dada mais ênfase às línguas modernas, não por um acréscimo em sua carga horária, mas pela diminuição da carga horária do latim. A grande mudança, porém, foi em termos de metodologia. Pela primeira vez introduzia-se oficialmente no Brasil o que tinha sido feito na França em 1901: instruções metodológicas para o uso do método direto, ou seja, o ensino da língua através da própria língua. ${ }^{2}$

A implantação do "método direto" ocorreu inicialmente no Colégio Pedro II, seguindo a tendência da Escola Nova, que buscava encontrar uma metodologia centrada na motivação e no aluno. Essa metodologia enfatizava os seguintes pontos: a importância de se ensinar a língua estrangeira utilizando a própria língua; a seqüência ouvir, falar, ler e escrever; o uso de gravuras e objetos para a explicação de palavras desconhecidas, evitandose a tradução; a compreensão do aluno das regras gramaticais pelo uso, e não pela explicação de tais regras; leitura de autores indicados, e também de manuais, revistas, almanaques e impressos que possibilitassem ao aluno conhecer o idioma como ele é utilizado no país de origem.

A Reforma Capanema, de 1942 (e as instruções que a seguiram), preocupou-se igualmente com a questão metodológica. Recomendou-se a utilização do "método direto" nas escolas públicas, mas indo além de

${ }^{2}$ Texto disponível em: <http:// www.leffa.pro.br>. Acesso em: 15 Jul. 2006. 
aspectos instrumentais. O próprio ministro Gustavo Capanema enfatizava que o ensino deveria propiciar ao aluno "uma sólida cultura geral, marcada pelo cultivo a um tempo das humanidades antigas e das humanidades modernas e, bem assim, de neles acentuar e elevar a consciência patriótica e a consciência humanística" (apud CHAGAS, 1967, p. 115).

A Reforma Capanema foi muito criticada por alguns educadores por suas características nacionalistas. Leffa (1999) ressalta que, no entanto, foi

(...) paradoxalmente, a reforma que deu mais importância ao ensino das línguas estrangeiras. Todos os alunos, desde o ginásio até o científico ou clássico, estudavam latim, francês, inglês e espanhol. Muitos terminavam o ensino médio lendo os autores nos originais e, pelo que se pode perceber através de alguns depoimentos da época, apreciando o que liam, desde as éclogas de Virgílio até os romances de Hemingway. Visto de uma perspectiva histórica, as décadas de 40 e 50, sob a Reforma Capanema, foram os anos dourados das línguas estrangeiras no Brasil.

\section{A Pedagogia Tecnicista}

A pedagogia tecnicista surge em meados do século XX, a partir dos pressupostos da neutralidade científica, inspirada na racionalidade técnica, e busca tornar o processo educativo objetivo e operacional de modo semelhante ao trabalho fabril (SAVIANI, 1986). A educação, nessa perspectiva, cumpre seu papel redentor ao contribuir para a superação da marginalidade à medida que forma cidadãos eficientes, que podem dar uma contribuição efetiva para a sociedade, aumentando a produtividade da economia. A marginalidade aqui é vista como ineficiência e improdutividade, constituindo-se como uma ameaça ao sistema. O que importa nessa pedagogia é o "aprender a fazer".

As décadas de 60 e 70 no Brasil foram marcadas por uma política educacional que priorizava a formação, no ensino médio, de especialistas capacitados para dirigir processos de produção ou utilizar as maquinarias envolvidas nesses processos. O ensino propunha uma profissionalização compulsória, que também tinha como finalidade diminuir o ingresso de alunos no ensino superior.

Por conta dessa orientação profissionalizante, as escolas diminuíram a carga horária destinada à LE, a não ser nos casos em que a "terminalidade" profissional envolvesse o estudo da LE, como na formação para "tradutor e intérprete”. Um parecer do Conselho Federal de Educação determinou 
que a língua estrangeira fosse dada por acréscimo, agravando ainda mais a situação das LEs nas escolas públicas. Muitas escolas preferiram retirar a língua estrangeira do $1^{\circ}$ grau, passando a oferecer não mais do que uma hora por semana, em alguns casos somente por um ano letivo. Um grande número de alunos terminou o $1^{\circ}$ e o $2^{\circ}$ graus (sobretudo os de supletivo) sem nunca terem visto uma língua estrangeira (LEFFA, 1999).

Diversos institutos de línguas nos anos 70 passaram a utilizar o método áudio-lingual, ou o audiovisual, uma metodologia semelhante ao "método direto", mas com o embasamento teórico advindo do behaviorismo e de uma concepção estruturalista de língua. Essa abordagem de ensino valoriza a língua como forma de interação social, em situações concretas, numa perspectiva instrumental. O método áudio-lingual, porém, chegou muito timidamente à escola pública, permanecendo mais restrito ao contexto das escolas particulares de ensino de idiomas.

Além da solução para os problemas da educação advir da técnica (traduzida pelo método eficaz), a escolha da língua estrangeira no currículo escolar também denotava a guinada do país para o desenvolvimento industrial, com a introdução da língua inglesa como LE majoritária nas escolas. O humanismo cedia lugar ao modelo de desenvolvimento econômico do pós-guerra.

\section{A Pedagogia Neoliberal}

Mais recentemente, como uma vertente a partir da pedagogia tecnicista, o neoliberalismo vem exercendo grande influência nas políticas educacionais, em grande parte por meio de agências internacionais como o Banco Mundial e o Fundo Monetário Internacional. Diversos autores (BIANCHETTI, 2005; SHIROMA et al., 2002; GISI, 2004; SILVA, 2004; PALMA FILHO, 2005), apontam a influência de tais agências, que mediante diagnósticos, análises e propostas de ajustes econômicos, definem os rumos da educação na América Latina, moldando uma nova ordem mundial globalizada.

Tais ajustes incluem cortes em políticas sociais e educacionais: o Estado não pode intervir na economia, que deve utilizar a lógica do mercado em todas as instâncias. Qualquer intervenção é vista como injusta, uma vez que tal lógica deve permear todas as relações sociais, não apenas as econômicas (BIANCHETTI, 2005; FRIGOTTO, 2005). É o mercado quem deve regular o capital e o trabalho, e considera a intervenção do estado como 
cerceadora dos princípios da individualidade e da liberdade, colocando as políticas sociais como as maiores responsáveis pela crise econômica dos países em desenvolvimento.

O neoliberalismo é uma retomada de princípios liberais surgidos na década de 40, como forma de combate ao ideário do Estado de Bem-estar e às teses keynesianas, ${ }^{3}$ principalmente no que se refere aos direitos sociais e às conquistas da classe trabalhadora. Com a crise e o colapso do socialismo nos anos 80, as idéias neoliberais ganham força, sobretudo com Reagan nos Estados Unidos e Margaret Tatcher na Inglaterra. As teses do "Estado Mínimo" - desregulamentação, privatização e total liberdade de mercado - se espalham pelo mundo inteiro (FRIGOTTO, 2005). O neoliberalismo dissemina a idéia de que não há alternativas viáveis a esse modelo políticoeconômico, a não ser adaptar-se a seus princípios.

Na economia competitiva, conforme Butler (1987 apudBIANCHETTI, 2005), "somente uma mistura de habilidade e sorte individuais poderá determinar a posição das pessoas na escala de rendas e riqueza". Os conceitos de justo e injusto não se aplicam à nova ordem social neoliberal, uma vez que os resultados da dinâmica da sociedade não são orientados para esse fim. Os resultados individuais e coletivos estão orientados pela sorte e pela decisão individual; a justiça, conforme salienta Bianchetti (2005, p. 91), é considerada "uma forma de intervenção externa na busca de uma igualdade de resultados, contrariando a concepção liberal que defende a idéia de igualdade de oportunidades". As desigualdades sociais são atribuídas à sorte e não às condições estruturais da sociedade. Assim, justificam-se os cortes orçamentários para as políticas sociais e educacionais. O pensamento neoliberal vê uma forma de compensação a essas desigualdades naturais apenas por meio de instituições de beneficência e de caridade, ou das fundações. Atualmente organizações do terceiro setor podem estar cumprindo em parte essa função.

\footnotetext{
${ }^{3}$ John Maynard Keynes (1883-1946), economista inglês, era a favor da intervenção do Estado na economia como forma de encontrar soluções para o desemprego. Isso seria feito por meios democráticos - sem que a economia capitalista fosse alterada fundamentalmente -, mediante o aumento da produção, o que geraria uma oferta maior de emprego. Keynes entendia que era necessário que o Estado orientasse o processo econômico, embora sem adquirir a propriedade dos meios de produção (LIMA FILHO, 2006).
} 
A educação, na concepção neoliberal, tem o papel de preparar indivíduos competentes e produtivos para esse mercado livre e competitivo. A noção de competência surge em contraposição ao conceito de qualificação profissional, no contexto da crise do capital e de busca para sua superação, modificando as relações entre capital e trabalho - definindo formas diferentes de remuneração e de produção. Os trabalhadores tinham, historicamente, se organizado em sindicatos fortes a partir de suas qualificações profissionais. O conceito de competências, centrada no indivíduo, dilui essa especificidade, rompendo a noção de classe e de sindicato, uma vez que cada indivíduo passaria a negociar sua inserção no mercado de trabalho (seu valor e suas condições) a partir de seu repertório de competências individuais. A escola passa a dar mais importância às particularidades individuais, respondendo às novas exigências da organização do trabalho (CARVALHO, 2005).

A pedagogia neoliberal estabelece um vínculo com a cidadania, mas uma cidadania baseada na livre expressão e na igualdade jurídica, "que confunde sociedade civil com mercado, prefere ver excluídose não desiguais e objetiva a adequação funcional de todos à lógica produtiva" (CARVALHO, 2005, p. 13). Há uma banalização do conceito de cidadania, desprovido que está de qualquer conotação de participação política, uma cidadania que vê apenas os direitos e deveres com relação ao estado e à sociedade, mas não prevê formas de participação política efetiva. Nas palavras de Gadotti (1997), "a pedagogia neoliberal é uma pedagogia da exclusão justamente porque reduz o pedagógico ao estritamente pedagógico, buscando retirar da pedagogia a sua essência política”.

No caso da língua estrangeira, o discurso da globalização passa a justificar, de modo mais contundente, as escolhas das línguas nas escolas, sem que haja, necessariamente, mudanças na metodologia proposta. A língua inglesa, como língua franca, assume caráter universalizante e se apresenta como requisito essencial no mercado de trabalho, que valoriza competências.

A TAB. 1, a seguir, traz um quadro sintético das principais tendências pedagógicas dentro da perspectiva da educação como redenção, mostrando como cada pedagogia vê a marginalidade a ser combatida, para que a harmonia social seja estabelecida. 
TABELA 1

Pedagogias e a Marginalidade

\begin{tabular}{|c|c|c|c|}
\hline & $\begin{array}{c}\text { Marginalidade } \\
\text { a ser combatida }\end{array}$ & $\begin{array}{l}\text { A educação e } \\
\text { o combate à } \\
\text { marginalidade }\end{array}$ & Professor/aluno \\
\hline $\begin{array}{l}\text { Pedagogia } \\
\text { Tradicional }\end{array}$ & Ignorância & $\begin{array}{l}\text { Saber conteudista: } \\
\underline{\text { aprender }}\end{array}$ & $\begin{array}{l}\text { O professor é o elemento } \\
\text { organizador,decisivo e decisório } \\
\text { do processo educacional }\end{array}$ \\
\hline Escola Nova & $\begin{array}{l}\text { Diferenças sociais, } \\
\text { anormalidades, } \\
\text { rejeição }\end{array}$ & $\begin{array}{l}\text { Inserção social, } \\
\text { valorização do } \\
\text { indivíduo: aprender } \\
\underline{\text { a aprender }}\end{array}$ & $\begin{array}{l}\text { Valorização da relação professor- } \\
\text { aluno; relação interpessoal e } \\
\text { intersubjetiva }\end{array}$ \\
\hline $\begin{array}{l}\text { Pedagogia } \\
\text { Tecnicista }\end{array}$ & $\begin{array}{l}\text { Ineficiência, } \\
\text { improdutividade }\end{array}$ & $\begin{array}{l}\text { Formação de indiví- } \\
\text { duos eficientes } \\
\text { produtivos; ênfase } \\
\text { na qualificação } \\
\text { profissional: } \\
\text { aprender a fazer }\end{array}$ & $\begin{array}{l}\text { Organização racional dos meios; } \\
\text { professor e aluno ocupam posição } \\
\text { secundária,executores; valorizção } \\
\text { de especialistas, neutros e } \\
\text { imparciais; behaviorismo }\end{array}$ \\
\hline $\begin{array}{l}\text { Pedagogia } \\
\text { Neoliberal }\end{array}$ & $\begin{array}{l}\text { Ineficiência, } \\
\text { improdutividade, } \\
\text { incompetência }\end{array}$ & $\begin{array}{l}\text { Preparar indivíduos } \\
\text { "competentes" para } \\
\text { competir no mercado } \\
\text { de trabalho e aptos } \\
\text { para o mercado de } \\
\text { consumo; ênfase no } \\
\text { indivíduo e suas } \\
\text { competências }\end{array}$ & $\begin{array}{l}\text { Ensinar é um ato exclusivamente } \\
\text { pedagógico, apolítico; ensinar } \\
\text { é desenvolver competências }\end{array}$ \\
\hline
\end{tabular}

\section{A educação como reprodução}

O primeiro grupo de teorias concebe a educação como uma forma de combater a marginalidade, que é vista como um problema social, um desvio que precisa ser corrigido. A educação - autônoma em relação à sociedade - estaria capacitada a torná-la melhor, corrigindo as injustiças e promovendo a equalização social. São teorias que consideram apenas a ação da educação sobre sociedade e desconhecem os condicionantes sociais no processo educacional (SAVIANI, 1986).

A educação como reprodução, ao contrário do primeiro grupo, entende o fenômeno educativo a partir de sua interdependência em relação à sociedade, uma instância dentro da sociedade que reproduz o modelo vigente, perpetuando-o: a educação é um elemento da própria sociedade, determinada pelos seus condicionantes sociais, políticos e econômicos 
(LUCKESI, 1994). Essa visão, de acordo com Saviani (1986) é crítica à medida que considera esses determinantes no processo educacional, mas de um ponto de vista pessimista, porque não vê uma saída para tal determinismo. É como se a educação estivesse fadada a simplesmente reproduzir a sociedade de classes e o modo de produção capitalista. Tais teorias não têm uma proposta pedagógica; apenas analisam o fenômeno educativo, entendendo-o como uma forma de reprodução dos próprios fatores que a condicionam. De acordo com Saviani (1986, p. 20), algumas das teorias que se incluem nessa tendência são:

a) a teoria do sistema de ensino enquanto violência simbólica;

b) a teoria da escola como AIE (Aparelho Ideológico do Estado);

c) a teoria da escola dualista.

Apenas para ilustrar essa tendência, abordaremos a teoria que trata a escola como um aparelho ideológico do Estado, conforme postulado por Althusser (2001). O autor analisa a reprodução das forças produtivas e das relações de produção, fazendo uma distinção entre os Aparelhos Repressivos do Estado - nos quais se incluem o governo, o exército, a polícia, as prisões, etc. - e os Aparelhos Ideológicos de Estado (AIE). Estes últimos incluem a igreja, as escolas públicas e privadas, a família, o sistema político, a mídia, a cultura e o sistema jurídico. Enquanto os Aparelhos Repressivos funcionam principalmente pela violência, os AIE funcionam, sobretudo, pela ideologia (materializada nos aparelhos).

A Escola, como um eficiente AIE, inculca nas crianças de todas as camadas da sociedade os saberes práticos necessários para a reprodução das relações de produção determinados pela ideologia dominante. Nas palavras de Althusser,

(...) a escola (mas também outras instituições do Estado, como a Igreja e outros aparelhos como o Exército) ensina o "know-how", mas sob formas que asseguram a submissão à ideologia dominante ou o domínio de sua "prática" (ALTHUSSER, 2001, p. 58).

A escola, segundo Althusser, (op. cit.) ensina um conhecimento que pode ser diretamente utilizável em diferentes postos da produção, "uma instrução para os operários, uma outra para os técnicos, uma terceira para os engenheiros, uma última para os quadros superiores, etc." (p. 58). Além dessas técnicas e conhecimentos, aprende-se na escola as regras de bom comportamento, isto é, 


\begin{abstract}
[a]s conveniências que devem ser observadas por todo agente da divisão do trabalho conforme o posto que ele esteja "destinado" a ocupar; as regras de moral e de consciência cívica e profissional, o que na realidade são regras de respeito à divisão social-técnica do trabalho e, em definitivo, regras de ordem estabelecida pela dominação de classe. Aprende-se também a "falar bem o idioma", a "redigir bem", o que na verdade significa (para os futuros capitalistas e seus servidores) saber "dar ordens", isto é, (solução ideal) dirigir-se adequadamente aos operários, etc. (ALTHUSSER, 2001, p. 58).
\end{abstract}

Althusser, (op. cit.) entende que não ocorre somente a reprodução da qualificação da força de trabalho mas também a reprodução da submissão dos futuros operários à ideologia dominante "por parte dos agentes da exploração e repressão" (p. 58). O predomínio da classe dominante é assegurado também pelo discurso.

Para muitos, ainda hoje o professor de línguas, sobretudo o de inglês (por se tratar de uma língua hegemônica), é visto como alguém que representa o "colonizador" em sala de aula. O professor, mentalmente colonizado, agiria como o vírus de computador chamado de "Cavalo de Tróia", invadindo as máquinas (as mentes dos alunos) para abrir caminho aos reais invasores, os "hackers" colonizadores (LEFFA, 2005).

Contudo, a conscientização de que a língua inglesa é hoje em dia uma língua franca, e vista não mais como a língua do colonizador somente, traz importantes mudanças na prática de sala de aula: a cultura do "outro" não é mais vista como a cultura a ser ensinada (e assimilada), mas é no encontro com "o outro" que nos vemos e construímos nossas próprias identidades (GIMENEZ, 2005). Essa percepção faz cair por terra também a idéia de que o modelo de LE a ser ensinado é o do falante nativo, já que todas as variantes lingüísticas são igualmente válidas.

\title{
A Educação como Transformação da Sociedade
}

Enquanto as teorias da tendência redentora pretendem resolver o problema da marginalidade de forma ingênua, sem nenhum êxito, as teorias crítico-reprodutivistas procuram explicar a razão de tal fracasso (SAVIANI, 1986). De fato, estas teorias entendem que a educação existe para reproduzir as relações de produção da sociedade capitalista, entre dominados e exploradores. A primeira visão é ingênua, e a segunda é pessimista. Conforme Saviani: 
[e]m ambos os casos, a História é sacrificada. No primeiro caso, sacrificase a História na idéia em cuja harmonia se pretende anular as contradições do real. No segundo caso, a História é sacrificada na reificação da estrutura social em que as contradições ficam aprisionadas (SAVIANI, 1986, p. 35).

Uma teoria crítica, transformadora, deveria ser formulada do ponto de vista dos interesses dos dominados, já que a classe dominante pretende apenas acionar mecanismos de adaptação que evitem a transformação (SAVIANI, 1986). A educação deve, nessa concepção, entender a escola como um instrumento que contribua para a superação da marginalidade, mas sem cair nas armadilhas colocadas pelos interesses dominantes, que não aceitam a transformação. Para Saviani:

(...) o caminho é repleto de armadilhas, já que os mecanismos de adaptação acionados periodicamente a partir dos interesses dominantes podem ser confundidos com os anseios da classe dominada. Para evitar esse risco, é necessário avançar no sentido de captar a natureza específica da educação que nos levará à compreensão das complexas mediações pelas quais se dá sua inserção contraditória na sociedade capitalista (SAVIANI, 1986, p. 36).

No contexto do ensino de línguas estrangeiras, esses mecanismos de adaptação, de que nos fala Saviani, se dariam por meio de discursos globalizantes, em sua maioria construídos em inglês, fortemente influenciados pelo capitalismo norte-americano. A mídia - como a televisão e a internet - cumpre o papel de disseminar tais discursos, reproduzindo e reforçando as relações de produção do mundo capitalista.

No entanto, alguns autores acreditam na força da transformação que pode advir do ensino da língua estrangeira. Para Moita Lopes (2003) e Leffa (2005) o professor de LEs tem um importante papel político. Professores e alunos precisam entender o mundo em que vivem, em seus aspectos políticos, sociais, econômicos e tecnológicos, para poder participar de uma educação transformadora. Segundo Moita Lopes (2003, p. 31), "não se pode transformar o que não se entende bem", acrescentando que "sem a compreensão do que se vive, não há política”. O ensino de línguas, e, portanto, o professor de LE, está no centro da vida contemporânea, dada a importância que a linguagem tem na vida social.

Moita Lopes (2003) salienta que há o perigo do discurso único, global, "que atravessa o mundo em tempo real, tornando as massas mais facilmente manipuláveis" (p. 35). O discurso da lógica neoliberal, do capitalismo 
global, transforma tudo em produtos a serem consumidos - incluindo a própria educação -, dando-nos a falsa impressão de que todos podem participar desse "grande bazar que se tornou a vida contemporânea" (p. 36), mas que na verdade beneficia apenas uma pequena parte da população mundial. Além disso, os discursos moldam nossas identidades sociais e determinam formas de participação política. O professor de línguas, nesse contexto, pode mediar a compreensão de como os discursos circulam nas práticas sociais, contribuindo para a desconstrução de discursos únicos, globais, e colaborando para a reconstrução de práticas sociais fundamentadas em princípios éticos.

\section{Os documentos oficiais e as tendências da educação}

Os textos produzidos pelo MEC para orientar o trabalho de professores representam visões sobre o papel da língua estrangeira na sociedade brasileira. Para a análise a que nos propusemos, selecionamos, sobretudo, excertos que tinham relação direta com a especificação de objetivos, uma vez que são eles que apontam mais claramente os propósitos que se pretende alcançar com o ensino de línguas estrangeiras.

Os objetivos expressos nos Parâmetros Curriculares Nacionais (PCNEF - Brasil, 1998) para o ensino de língua estrangeira, terceiro e quarto ciclos do ensino fundamental, acompanhando a tendência da globalização e do conceito de "cidadania global", ressaltam a importância da integração do indivíduo no mundo, conhecendo diferentes culturas. Aqui a idéia é redimir o mundo todo, não mais as sociedades locais, de suas mazelas. Aprender uma LE é uma forma de fazer parte do mundo, de ser um cidadão global, com direitos e deveres para com essa sociedade plural e mundial. Tais objetivos são orientados pelos seguintes focos: o mundo multilíngüe e multicultural em que o aluno vive; a compreensão global (escrita e oral); e o empenho na negociação do significado e não na correção. Os objetivos a seguir, extraídos dos PCNEF (1998) de Língua Estrangeira, ilustram essa visão:

[v]ivenciar uma experiência de comunicação humana, pelo uso de uma língua estrangeira, no que se refere a novas maneiras de se expressar e de ver o mundo, refletindo sobre os costumes ou maneiras de agir e interagir e as visões de seu próprio mundo, possibilitando maior entendimento de um mundo plural e de seu próprio papel como cidadão de seu país e do mundo ( p. 67); 
[r]econhecer que o aprendizado de uma ou mais línguas lhe possibilita o acesso a bens culturais da humanidade construídos em outras partes do mundo (p. 67);

[i]dentificar no universo que o cerca, as línguas estrangeiras que cooperam nos sistemas de comunicação, percebendo-se como parte integrante de um mundo plurilíngüe e compreendendo o papel hegemônico que algumas línguas desempenham em determinado momento histórico (p. 66).

O último objetivo citado menciona o papel hegemônico das línguas estrangeiras em determinado momento histórico. Seria entendido como um objetivo que desenvolve a consciência crítica do aluno, à medida que poderia questionar as relações de poder entre os países e as desigualdades na qualidade de vida de alguns grupos sociais em relação a outros, investigando as causas e as conseqüências de tal hegemonia. Contudo, ao restringir a compreensão como objetivo, deixa de explorar as possibilidades de transformação a partir do questionamento da ordem vigente.

Os Temas Transversais (BRASIL, 1998), que complementam os PCNEF (BRASIL, 1998), propõem uma educação para a cidadania por meio de questões sociais para a reflexão dos alunos, temas que podem ser contextualizados e priorizados conforme as diferentes realidades locais e regionais. O documento aprofunda o debate sobre a questão da cidadania, relacionada "com a discussão sobre o significado e o conteúdo da democracia, sobre perspectivas e possibilidades de construção de uma sociedade democrática" (p. 20). A noção de cidadania trazida pelos Temas Transversais amplia a compreensão do cidadão como portador de direitos e deveres para alguém que produz tais direitos e cria condições para a possibilidade de participação da gestão pública. O documento aponta para a necessidade de transformação da sociedade em suas dimensões econômica, política e cultural, elegendo para isso os seguintes princípios: dignidade da pessoa humana; igualdade de direitos; participação (cidadania ativa) e co-responsabilidade pela vida social. Os temas sugeridos são a ética, a pluralidade cultural, o meio ambiente, a saúde, a orientação sexual, e o trabalho e consumo.

As novas Orientações Curriculares para o Ensino Médio - Língua Estrangeira (OCEM - LE) aprofundam as discussões em torno da questão da cidadania e do papel educacional das línguas estrangeiras na escola pública, da inclusão e da exclusão, do global e do local - uma reflexão 
sobre o aprendizado de LEs numa sociedade globalizada. A proposta pretende aproveitar as contribuições trazidas pelos PCNs (1998), sobretudo os Temas Transversais, partindo do princípio de que "seria incoerente abandonar por completo o conhecimento anterior dos leitores deste documento, substituindo-o pelo 'novo'(p. 110).

As OCEM-LE reconhecem o papel educacional da língua estrangeira e propõem o letramento crítico como suporte teórico para a inclusão social. Para os autores do documento, "a exclusão está implícita em concepções de língua e cultura como totalidades abstratas, fixas, estáveis e homogêneas" (p. 96).

Ao salientar que o "valor educacional da aprendizagem de uma língua estrangeira vai muito além de meramente capacitar o aprendiz a usar uma determinada língua estrangeira para fins comunicativos" (p. 86), a proposta do documento é que o ensino de língua estrangeira trabalhe a favor da inclusão. Embora reconhecendo que vários fatores concorrem para a exclusão, admite que essa inclusão poderá ser "por meio do ensino de línguas estrangeiras por si mesmo, atendendo a objetivos lingüísticos e instrumentais". No entanto, prosseguem os autores na argumentação de que outros objetivos (culturais e educacionais) poderão contribuir de modo valioso, porque propõem "trabalhar no âmbito da formação de indivíduos, de cidadãos - se focalizar um aspecto já mencionado anteriormente: o de trabalhar em prol de uma "alfabetização" dos alunos (indivíduos, cidadãos) (SOARES, 2004), condizente com as necessidades da sociedade (grifo nosso), porque é interpelada por uma história e uma cultura em constante construção e reconstrução" (p. 97).

Observe-se que essa proposta, apesar de salientar aspectos de desigualdades sociais pelo paradigma da inclusão/exclusão, não nega a instrumentalização lingüistica - acrescenta-lhe valores educacionais e culturais em sintonia com as necessidades da sociedade. Ao não problematizar os conflitos inerentes às sociedades marcadas por profundas desigualdades e focalizar o problema como sendo de consciência crítica sobre heterogeneidade discursiva e diversidade sociocultural, as OCEM LE parecem se alinhar - paradoxalmente - com as tendências redentora e transformadora.

O documento preconiza que a transformação social pode ser operada a partir de um ensino que desperte a consciência crítica para as diferentes visões de mundo expressas na e pela linguagem, mas admite 
que um bom aprendizado da língua para uso em situações de comunicação também pode proporcionar a inclusão social.

Outra postura é adotada no documento dedicado ao Espanhol. As Orientações Curriculares para o Ensino Médio, Conhecimento de Espanhol (OCEM-CE), trazem uma perspectiva que enfatiza aspectos educacionais do ensino de línguas, entendendo que "que a função maior de uma língua estrangeira no contexto escolar é a de contribuir para a formação do cidadão" (p. 146). A orientações acrescentam ainda que a proposta considera

o papel educativo que pode ou deve ter o ensino de línguas, em especial do Espanhol, na formação do estudante, naquilo que este lhe proporciona em termos de inclusão social e étnica, na constituição de sua cidadania (OCEM-CE, p. 129).

O documento não traz, contudo, um elenco de objetivos educacionais explícitos a serem atingidos com o ensino de espanhol no ensino médio, sendo genérico em relação a eles. Alguns deles podem ser inferidos, mas não são claramente expressos em termos de objetivos. Traz, por outro lado, longas considerações sobre qual variante da língua espanhola deve ser ensinada, e aponta para a necessidade de substituirmos o discurso hegemônico "pela pluralidade lingüística e cultural do universo hispanofalante" (OCEM-EC, p. 134). As OCEM-CE não pretendem apresentar uma proposta metodológica específica, atividades e seqüências de conteúdos, mas, "acima de tudo, proporcionar algumas reflexões de caráter teórico-prático que nos levem a compreender um pouco mais os conflitos inerentes à educação, ao ato de ensinar, à cultura que consolida a profissão de professor" (p. 129).

Por um lado, ao mesmo tempo em que as OCEM-CE advogam que o ensino de LEs deva "ocupar um papel diferenciado na construção coletiva do conhecimento e na formação do cidadão" (p. 131), reiterando os objetivos da Carta de Pelotas (segundo os quais o ensino de LEs não deve atender apenas a objetivos instrumentais), por outro lado, propõem o desenvolvimento de competências e habilidades, a saber: competência (inter)pluricultural; competência comunicativa; compreensão oral; produção oral; compreensão leitora; e produção escrita. O enfoque educacional proposto nos parece instrumental, embora o documento afirme que "o foco do ensino não pode estar, ao menos de modo exclusivo e predominante, na preparação para o trabalho ou para a superação de provas seletivas, como o vestibular" (p.147). 
Não podemos afirmar, assim, que as OCEM-CE tenham de fato um caráter transformador na perspectiva de Saviani (1986). Trazem uma perspectiva educacional que oscila entre a pedagogia neoliberal, voltada para o desenvolvimento de competências (e também para o mercado de trabalho), e uma perspectiva humanista, redentora, que busca a inserção do aluno cidadão num mundo multicultural, não chegando realmente a problematizar as grandes desigualdades que marcam nossa sociedade.

Desse modo, é possível dizer que há traços das tendências de redenção e transformação nos documentos oficiais analisados, o que evidencia que essas tendências não são vistas como excludentes. Se, por um lado, o aprendizado bem-sucedido de uma língua estrangeira pode levar à inclusão em esferas de comunicação antes não possibilitadas pelo monolinguismo; por outro lado, esse aprendizado não traz necessariamente a semente da transformação.

\section{Considerações Finais}

Como vimos, ao longo deste trabalho, a educação e sua relação com a sociedade pode ser entendida por meio de três tendências: a educação como redenção, aqui analisada na pedagogia tradicional, na escola nova, na pedagogia tecnicista e na pedagogia neoliberal; a educação como reprodução das estruturas e das relações de produção da sociedade; e a educação como transformação da sociedade. A primeira vê a educação como independente da sociedade e busca várias formas de resolver o problema da marginalidade com uma expectativa otimista, porém ingênua, que Saviani (1986) chama de não-crítica. Os teóricos da tendência críticoreprodutivista concebem a educação como parte da sociedade e consideram os fatores econômicos, políticos, históricos e sociais como parte integrante do processo educacional; contudo, não apresentam nenhuma proposta pedagógica e têm uma postura pessimista, já que entendem que a escola está fadada a reproduzir as relações de produção da sociedade. A terceira tendência vê a educação e sociedade de forma integrada, buscando também a superação do problema da marginalidade, porém do ponto de vista das classes menos favorecidas, dominadas política e economicamente.

Desde o tempo em que estávamos sob o jugo português, o ensino de línguas estrangeiras no Brasil vem passando por transformações. De uma época em que servia a uma classe dominante (que precisava estudar no exterior ou circular pelos salões europeus com desenvoltura) até chegar 
aos nossos dias, em que seu aprendizado tem sido freqüentemente equacionado com a língua inglesa, foram muitas as mudanças sociais. Durante o Império e mesmo durante o início da República, aprender língua estrangeira era algo reservado à minoria. As línguas clássicas e européias modernas eram privilegiadas em um currículo voltado para o desenvolvimento cultural e humanístico. Com o processo de industrialização do país e a democratização da escola, os objetivos de aprendizado da língua estrangeira voltaram-se para questões mais instrumentais. A sociedade passou a valorizar seu aprendizado como forma de aumentar o capital simbólico no mercado de trabalho. A legislação, contudo, não acompanhou esses desenvolvimentos e previa que a comunidade escolar deveria escolher qual língua estrangeira ensinar. O francês deu lugar ao inglês na década de 70, acompanhando a tendência do país em alinhar-se culturalmente aos Estados Unidos no pós-guerra.

Começava aí se desatrelar o ensino da língua estrangeira a uma função de enriquecimento cultural e iniciava-se um processo de crescente interesse em tornar seu aprendizado mais imediato e voltado para situações de comunicação específicas, em função das demandas trazidas pelos processos de internacionalização da economia. Florescem as escolas de línguas particulares diante do fracasso da escola regular em cumprir esses objetivos.

A tendência atual no ensino de LEs é a de problematizar com os alunos questões de relevância social, de forma a desconstruir discursos hegemônicos, globalizantes, e de propiciar o desenvolvimento de uma consciência crítica que permita uma maior participação social e política. Os professores de LEs, conforme Leffa (2005) e Moita Lopes (2003), têm um importante papel político nas escolas, à medida que são mediadores do processo construção de sentidos pelos alunos e de questionamento desses discursos hegemônicos - em sua maioria produzidos em língua inglesa que circulam em tempo real pelo mundo todo, devido ao grande desenvolvimento tecnológico dos últimos anos.

Para tentar resolver essas questões, as autoridades educacionais a cada década divulgam orientações curriculares sem que, contudo, os professores consigam conciliar os objetivos ali expressos com a realidade da sala de aula. O conflito dos diferentes papéis que a língua estrangeira tem na sociedade se revela até mesmo em uma única fonte, que são os documentos oficiais. Quando levados para a sala de aula, mesclam-se com os objetivos dos próprios alunos, que podem ter outras visões sobre esses papéis. 
Amplia-se o conflito à medida que diversos interesses são representados por diferentes grupos sociais, ampliando a multiplicidade de perspectivas sobre a relação entre o aprendizado de uma língua estrangeira e a sociedade. Analisar parâmetros ou orientações curriculares sob esse prisma nos permite vislumbrar, de modo mais claro, esses embates.

\section{Bibliografia}

ALTHUSSER, L. Aparelhos ideológicos de Estado: nota sobre os aparelhos ideológicos de Estado. Rio de Janeiro: Graal, 2001.

BIANCHETTI, R. G. Modelo Neoliberal e Políticas Educacionais. 4. ed. São Paulo: Cortez Editora, 2005.

BRASIL. Ministério da Educação. Secretaria de Educação Fundamental. Parâmetros curriculares nacionais: terceiro e quarto ciclos do ensino do ensino fundamental: lingua estrangeira/Secretaria de Educação Fundamental. - Brasília: MEC/SEF, 1998.

Ministério da Educação. Secretaria de Educação Fundamental.

Parâmetros curriculares nacionais: terceiro e quarto ciclos: apresentação dos temas transversais /Secretaria de Educação Fundamental. - Brasília: MEC/SEF, 1998.

. Ministério da Educação. Secretaria de Educação Média e Tecnológica. Parâmetros curriculares nacionais: ensino médio. Brasília: MEC/SEMTEC, 1998.

BUTLER, E. Hakey: as idéias políticas e econômicas de nosso tempo. Rio de Janeiro: Nórdica, 1987. Apud BIANCHETTI, R. G. Modelo Neoliberal e Políticas Educacionais. 4. ed. São Paulo: Cortez Editora, 2005.

CANALE, M.; SWAIN, M. Theoretical bases of communicative approaches to second language teaching and testing. In: Applied Linguistics, 1(1), 1980.

CHAGAS, R. V. C. Didática especial de línguas modernas. São Paulo: Companhia Editora Nacional, 1967.

CARVALHO, C. O trabalho educativo no contexto das reformas do ensino médio na década de 1990. CONGRESSO INTERNACIONAL EDUCAÇÃO E TRABALHO: REPRESENTAÇÕES SOCIAIS, COMPETÊNCIAS E TRAJETÓRIAS PROFISSIONAIS. Anais... Aveiro, Portugal, 2005, v. 1, p.35-58. 
CHOMSKY, N. Aspectos da Teoria da Sintaxe. In: SAUSSURE, F.; JAKOBSON, R.; HJELMSLEV, L. T.; CHOMSKY, N. Textos Selecionados / Coleção Os Pensadores. 3. ed. São Paulo: Abril Cultural, 1985.

FERREIRA, N. S. C. Políticas de ensino e políticas de formação: compromissos da gestão da educação. In: ROMANOWSKI, J. P.; MARTINS, P. L.; JUNQUEIRA, J. P. (Org.). Conhecimento Local e conbecimento universal. Curitiba: Champagnat, 2004. v. 4, p. 257-268.

FRANCA, Leonel. O método pedagógico dos jesuitas. Rio de Janeiro: Agir, 1952. Apud LEFFA, V. J. O ensino de línguas estrangeiras no contexto nacional. Contexturas, APLIESP, n. 4, p. 13-24, 1999.

FRIGOTTO, G. Prefácio. In: BIANCHETTI, R. G. Modelo Neoliberal e Politicas Educacionais. 4. ed. São Paulo: Cortez Editora, 2005.

GADOTTI, M. LIÇÕES DE FREIRE. Rev. Fac. Educ. [online]. Jan./Dec. 1997, v.23, n.1-2. Disponível em: < http://www.scielo.br/scielo.php?pid=S010225551997000100002\&script=sci_arttext\&tlng=pt>. Acesso em: 13 Jul. 2006.

GIMENEZ, T. Línguas Estrangeiras Modernas - Questões para Debate. In: Diretrizes Curriculares da Educação Fundamental da Rede de Educação Básica do Estado do Paraná. Curitiba: Secretaria do Estado do Paraná, 2005. p. $168-173$.

GISI, M. L. Acesso e permanência na educação superior: as políticas educacionais em questão. In: ROMANOWSKI, J. P.; MARTINS, P. L.; JUNQUEIRA, J. P. (Org.). Conhecimento Local e conhecimento universal. Curitiba: Champagnat, 2004. p. 257-268.

LEFFA, V. J. O ensino de línguas estrangeiras no contexto nacional. Contexturas, APLIESP, n. 4, p. 13-24, 1999.

O professor de línguas estrangeiras: do corpo mole ao corpo dócil. In: FREIRE, M. M.; ABRAHÃO, M. H. V.; BARCELOS, A. M. F. (Org.). Lingüística Aplicada e contemporaneidade. São Paulo: ALAB/Pontes, 2005. p. 203-218.

LIMA FILHO, F. das C. O Estado Social: modelo espanhol e modelo brasileiro. Revista O Trabalbo, Curitiba, ano 24, p. 3094, jan. 2006.

HYMES, D. On Communicative Competence. In: PRIDE, J. B.; HOMES, J. (Org.). Sociolinguistics. Harmondsworth: Penguin, 1972.

LUCKESI, C. C. Filosofia da Educação. São Paulo: Cortez. 1994. 
MOITA LOPES, L. P. de. A nova ordem mundial, os parâmetros curriculares nacionais e o ensino de inglês no Brasil: a base intelectual para uma ação política. In: BARBARA, L.; RAMOS, R. C. G. (Org.). Reflexão e Ações no Ensinoaprendizagem de Linguas. São Paulo: Mercado de Letras, 2003. p. 29-57.

PALMA FILHO, J. C. A Política nacional de formação de professores. In: BARBOSA, R. L. L. (Org.). Trajetórias e perspectivas da formação de educadores. São Paulo: Editora UNESP, 2005.

SAVIANI, D. Escola e Democracia. São Paulo: Cortez Editora, 1986.

SHIROMA, E. O.; MORAES, M. C. M. de. Política Educacional. 2. ed. Rio de Janeiro: DP\&A, 2002.

SILVA, W. C. da. Formação de Professores para a educação básica na universidade e as políticas neoliberais. In: LINHARES, C. F. S. (Org.). Formação continuada de professores: comunidade científica e poéticauma busca de São Luís do Maranhão. Rio de Janeiro: DP\&A, 2004. p. 113-132.

SOARES, M. Letramento: um tema em três gêneros. Belo Horizonte: Autêntica, 2004. 